Pacific Journal of Mathematics

A REFINEMENT OF THE FUNDAMENTAL THEOREM ON THE
DENSITY OF THE SUM OF TWO SETS OF INTEGERS 


\title{
A REFINEMENT OF THE FUNDAMENTAL THEOREM ON THE DENSITY OF THE SUM OF TWO SETS OF INTEGERS
}

\author{
H. B. MANN
}

Let $A=\left\{a_{0}<a_{1}<\cdots\right\}$ be a set of integers and let $A(n)$ be the number of integers in $A$ not exceeding $n$. If $A, B$ are two such sets, we put $A+B=\{a+b\}$, where $a$ denotes generically an element of $A$, $b$ an element of $B$. It should be noted that $A$ and $B$ may contain negative numbers or zero and that these are counted in $A(n)$ and $B(n)$.

Erdoes in an unpublished paper proved:

If $\lim _{m \rightarrow \infty}(A(m) / m)=\lim _{m \rightarrow \infty}(B(m) / m)=0$, then for every $\varepsilon>0$ there are infinitely many $x$ such that if $C=A+B$ then

$$
C(x) \geq A(x)(1-\varepsilon)+B(x) .
$$

Clearly there are then also infinitely many $y$ such that

$$
C(y) \geq A(y)+B(y)(1-\varepsilon) .
$$

Erdoes conjectured that it is possible to choose infinitely many $x=y$.

At the Number Theory Conference in Boulder, Colorado, Erdoes proposed this problem to the author. It is clear that the Fundamental Theorem [3] is inadequate to deal with this problem, because it fails if $1 \notin C$. The search for a stronger theorem finally led the author to Theorem 2. Theorem 3 is a consequence of Theorem 2 and is considerably stronger than Erdoes conjecture.

Theorem 1. Let $a_{0}=b_{0}=0$. If $n \geq 0, n \notin C$ then there is an $m \notin C$, $m=n$ or $m<(n / 2)$, such that

$$
\frac{C(n)}{n+1} \geq \frac{A(m)+B(m)-1}{m+1}+\left(C(n-m-1)-\frac{C(n)}{n+1}(n-m)\right) \frac{1}{m+1} .
$$

For the proof of Theorem 1, we consider the following transformation: Let $n_{1}<n_{2}<\cdots<n_{r}=n$ be the gaps in $C$. Form $d_{i}=n-n_{i}$. Choose, if possible, a fixed number $e \in B$ such that an equation

$$
a+e+d_{i}=n_{j}
$$

holds for some $i$. Let the set $B^{\prime}$ consist of all numbers $e+d_{s}$ for which 
an equation $a+e+d_{s}=n_{t}$ holds with some value of $a$. Form $B^{*}=$ $B^{*}(e)=B \cup B^{\prime}, C^{*}=A+B^{*}$. The following propositions are easily seen to hold.

\section{Proposition 1. $n \notin C^{*}$.}

Proof. The equation $a+e+d_{s}=n$ implies $a+e=n_{s}$, which is impossible since $e \in B$.

\section{Proposition 2. $B^{\prime} \cap B$ is empty.}

Proof. The equation $a+e+d_{s}=n_{t}$ shows that $e+d_{s} \notin B$.

Proposition 3. $C^{*}(n)-C(n)=B^{*}(n)-B(n)$.

Proof. The equation $a+e+d_{s}=n_{t}$ implies $a+e+d_{t}=n_{s}$. Hence if $n_{s} \in C^{*}$ then $e+d_{s} \in B^{1}$ and vice versa.

Proposition 4. All numbers of $B^{\prime}$ are larger than $e$.

Proof. $B^{\prime}$ consists of numbers of the form $e+d_{s}, d_{s}>0$.

$B^{*}(e)$ is called the fundamental $e$ transform of $B$.

We now construct numbers $e_{1}, \cdots, e_{k}$ and sets $B=B_{0}, B_{1}, \cdots, B_{k}$, $C=C_{0}, C_{1}, \cdots, C_{k}$ by the following rules:

Rule 1. $B_{j}$ is the fundamental $e_{j}$ transform of $B_{j-1}$.

Rule 2. $A+B_{j}=C_{j}$.

Rule 3. $e_{j}$ is the smallest number in $B_{j-1}$ such that an equation

$$
a+e_{j}+d_{s}=n_{t}, a \in A, n_{s}, n_{t} \notin C_{j-1}
$$

holds.

Rule 4. $a+e+d_{s} \neq n_{t}$ for any $a \in A, e \in B_{k}, n_{s}, n_{t} \notin C_{k}$. We then have

Proposition 5. $\quad e_{1}<e_{2}<\cdots<e_{k}$.

Proof. We have $a+e_{j}+d_{s}=n_{t} ; a \in A, n_{s}, n_{t} \notin C_{j-1}, e_{j} \in B_{j-1}$. If $e_{j} \notin B_{j-2}$ then $e_{j}>e_{j-1}$ (Prop. 4). If $e_{j} \in B_{j-2}$ then since $C_{j-1} \supset C_{j-2}$ the inequality $e_{j}<e_{j-1}$ contradicts rule 3 , while $e_{j}=e_{j-1}$ implies $n_{s}, n_{t} \in C_{j-1}$.

For any set $A$ put

$$
A(m, n)=A(n)-A(m-1) .
$$

Lemma 1. Let $n_{s}$ be the least gap in $C_{k}$, then

$$
\begin{aligned}
B_{k}\left(n_{s}\right)-B\left(n_{s}\right) & =C_{k}\left(d_{s}, n\right)-C\left(d_{s}, n\right) \\
& =n_{s}-C\left(d_{s}, n\right) .
\end{aligned}
$$


Proof. Let $d_{r-1}, \cdots, d_{r-q}, \leq n_{s}, d_{r-q-1}>n_{s}$ where we formally set $d_{0}=n+1$. If $d_{j} \leq n_{s}$ then $n_{s}-d_{j} \in C_{k}, n_{s}-d_{j}=a+b^{*}, b^{*} \in B_{k}$. Hence by rule 4 we have $n_{j} \in C_{k}$. But $d_{j} \leq n_{s}$ implies $d_{s} \leq n_{j}$ hence

$$
C_{k}\left(d_{s}, n\right)-C\left(d_{s}, n\right)=q .
$$

Moreover $C_{k}$ contains all numbers $x$ for which $d_{s} \leq x<n$, but does not contain $n$ so that $C_{k}\left(d_{s}, n\right)=n-\left(d_{s}-1\right)-1=n_{s}$.

On the other hand if $n_{j} \in C_{\alpha}, n_{j} \notin C_{\alpha-1}$ then $e_{\alpha}+d_{,} \in B_{\alpha}, e_{\alpha}+d_{,} \notin B_{\alpha-1}$, (Prop. 2). If $d_{j} \leq n_{s}$ and $e_{\alpha}+d_{f}>n_{s}$ then

$$
e_{\alpha}>n_{s}-d_{f}=a+b^{*}, b^{*} \in B_{k} .
$$

By Prop. 4 and $5, b^{*} \in B_{\alpha-1}$ and $e_{\alpha}>b^{*}$ contradicts rule 3 . Hence

$$
B_{k}\left(n_{s}\right)-B\left(n_{s}\right)=q \text {. }
$$

This completes the proof of Lemma 1 .

We are now prepared for the proof of Theorem 1 . Since $n_{s}$ is not in $C_{k}$ no number of the form $n_{s}-a$ is in $B_{k}$ and therefore

$$
n_{s}+1 \geq A\left(n_{s}\right)+B_{k}\left(n_{s}\right) \text {. }
$$

Subtracting 4 from 7 we get

$$
C(n) \geq C\left(d_{s}-1\right)+A\left(n_{s}\right)+B\left(n_{s}\right)-1
$$

which after some simple algebra gives

$$
\frac{C(n)}{n+1} \geq \frac{A\left(n_{s}\right)+B\left(n_{s}\right)-1}{n_{s}+1}+\left(C\left(d_{s}-1\right)-\frac{C(n)}{n+1} d_{s}\right) \frac{1}{n_{s}+1} .
$$

Finally if $n_{s}<n$ then because of rule 4 we must have $n_{s}<d_{s}=$ $n-n_{s}, n_{s}<n / 2$. This completes the proof of Theorem 1 .

Theorem II. Let $A+B=C, a_{0}=b_{0}=0, n \geq 0$. Then either $C(n)=$ $n+1$ or there exist numbers $m, m_{1}$ satisfying the conditions

$$
\begin{gathered}
\frac{C(n)}{n+1} \geq \frac{A(m)+B(m)-1}{m+1}+\left|\frac{C(n)}{n+1}-\frac{C\left(m_{1}\right)}{m_{1}+1}\right| \\
m \notin C, m \leq n, m_{1} \notin C, m_{1} \leq \max (m, n-m-1) .
\end{gathered}
$$

Proof. The theorem is true if $n=0$. Hence we can apply induction on $n$. If for any $m \notin C, m<n$ we have $C(n) /(n+1) \geq C(m) /(m+1)$ then by induction 


$$
\begin{aligned}
\frac{C(n)}{n+1}=\left|\frac{C(n)}{n+1}-\frac{C(m)}{m+1}\right|+\frac{C(m)}{m+1} \\
\geq\left|\frac{C(n)}{n+1}\right|-\frac{C(m)}{m+1} \mid+\frac{A\left(m_{1}\right)+B\left(m_{1}\right)-1}{m_{1}+1} \\
+\left|\frac{C(m)}{m+1}-\frac{C\left(m_{2}\right)}{m_{2}+1}\right| \\
\geq\left|\frac{C(n)}{n+1}-\frac{C\left(m_{2}\right)}{m_{2}+1}\right|+\frac{A\left(m_{1}\right)+B\left(m_{1}\right)-1}{m_{1}+1},
\end{aligned}
$$

where $m_{2} \notin C, m_{1} \notin C, m_{2} \leq \max \left(m_{1}, m-m_{1}-1\right) \leq \max \left(m_{1}, n-m_{1}-1\right)$.

Now assume $C(n) \neq n+1$ and

$$
\frac{C(n)}{n+1}<\frac{C(m)}{m+1}
$$

for all $m<n, m \notin C$. If $n \in C$ then $C(n) /(n+1)>C(n-1) / n$ hence (9) implies $n \notin C$. We apply Theorem 1 . If in Theorem $1 m=n$ then Theorem 2 holds with $n=m=m_{1}$. If $m<n / 2$ in Theorem 1 , then $n-m-1 \geq m$, hence there is a largest $m_{1} \leq n-m-1, m_{1} \notin C$. We then have

$$
\frac{C(n-m-1)}{n-m} \geq \frac{C\left(m_{1}\right)}{m_{1}+1} \text {. }
$$

Moreover since $(n-m) /(m+1) \geq 1$ we get from Theorem 1

$$
\begin{aligned}
\frac{C(n)}{n+1} & \geq \frac{C\left(m_{1}\right)}{m_{1}+1}-\frac{C(n)}{n+1}+\frac{A(m)+B(m)-1}{m+1} \\
& =\left|\frac{C(n)}{n+1}-\frac{C\left(m_{1}\right)}{m_{1}+1}\right|+\frac{A(m)+B(m)-1}{m+1}
\end{aligned}
$$

and Theorem 2 is proved.

Theorems 1 and 2 can easily be generalized for arbitrary $a_{0}, b_{0}$. One simply applies the two theorems to the set $A^{\prime}=\left(A-a_{0}\right), B^{\prime}=\left(B-b_{0}\right)$. If $a_{0}+b_{0}=c_{0}$ then $C^{\prime}(n)=C\left(n+c_{0}\right), A^{\prime}(m)=A\left(m+a_{0}\right), B^{\prime}(m)=B\left(m+b_{0}\right)$. After some fairly obvious transformation Theorem 2 then reads

TheOREM 2a. Let $A=\left\{a_{0}<a_{1}<\cdots\right\}, B=\left\{b_{0}<b_{1}<\cdots\right\}, A+B=$ $C=\left\{c_{0}<c_{1}<\cdots\right\}$. Let $n \geq c_{0}$. Either $C(n)=n-c_{0}+1$ or there exist $m, m_{1}$ satisfying the conditions:

$$
\begin{aligned}
\frac{C(n)}{n-c_{0}+1} \geq & \frac{A\left(m-b_{0}\right)+B\left(m-a_{0}\right)-1}{m-c_{0}+1} \\
& +\left|\frac{C(n)}{n-c_{0}+1}-\frac{C\left(m_{1}\right)}{m_{1}-c_{0}+1}\right|,
\end{aligned}
$$


$c_{0}<m \leq n, m \notin C, m_{1} \notin C, c_{0}<m_{1} \leq \max \left(m, n-m+c_{0}-1\right)$.

It is worth noting that Theorem 2 implies the Fundamental theorem proved in [3]. We shall prove the following

Corollary to Theorem 2. Let $a_{0}=b_{0}=0, n \notin C, \gamma(n)=C(n)-1$, $\sigma(m)=A(m)+B(m)-2$. Then either $\gamma(n) \geq \sigma(n)$ or $\gamma(n) / n>\sigma(m) / m$ for some $m \notin C, 0<m<n$.

Proof. Let $m$ be the integer of Theorem 2. If $\mathrm{n}=m$ then Theorem 2 reads $\gamma(n) \geq \sigma(n)$. If $\gamma(n)<\sigma(n)$ then Theorem 2 yields

$$
\gamma(n) m+\gamma(n)+m \geq \sigma(m) n+\sigma(m)+n \text {. }
$$

If $\gamma(n) m \leq \sigma(m) n$ then we obtain from this $\gamma(n)+m \geq \sigma(m)+n$, $\sigma(m) n+m^{2} \geq \sigma(m) m+n m$ and therefore $\sigma(m) \geq(m)$. Hence $C(n) \geq n+1$, which is impossible since $n \notin C$. This proves the corollary.

We shall now prove Theorem 3. If $\underline{\lim }((A(m)+B(m)) / m=0$, then there are infinitely many $m$ such that

$$
C(m) \geq A\left(m-b_{0}\right)+B\left(m-a_{0}\right)-1 .
$$

If $C$ has only finitely many gaps above $c_{0}$, then Theorem 3 is obvious. There is an infinite sequence of $m_{i}$ such that

$$
\frac{A\left(m_{i}-b_{0}\right)+B\left(m_{i}-a_{0}\right)-1}{m_{i}-c_{0}+1}<\frac{A\left(m-b_{0}\right)+B\left(m-a_{0}\right)-1}{m-c_{0}+1}
$$

for $c_{0} \leq m<m_{i}$. It follows from Theorem $2 \mathrm{a}$ that

$$
C\left(m_{i}\right) \geq A\left(m_{i}-b_{0}\right)+B\left(m_{i}-a_{0}\right)-1 .
$$

(If $m_{i} \notin C$ this follows directly from Theorem $2 \mathrm{a}$. If $m_{i} \in C$ take the next gap in $C$ below $m_{i}$.)

Theorem 4. If $A+B=C$ and $\underline{\lim }(C(n) / n=0$, then

$$
\varliminf_{m \in o} \frac{A(m)+B(m)}{m}=0
$$

and 10 holds for infinitely many $m \notin C$.

Proof. Without loss of generality we may assume $a_{0}=b_{0}=0$. There is an infinite sequence $\left\{n_{i}\right\}$ such that $C\left(n_{i}\right) /\left(n_{i}+1\right)<C(m) /(m+1)$ for $m<n_{i}$. Clearly $n_{i} \notin C$. Let $m_{i}$ be the value of $m$ of Theorem 1 corresponding to $n_{i}$. From Theorem 1 we see that the values $m_{i}$ also form an infinite sequence, since $A(m)+B(m)-1$ cannot vanish and since 
by assumption $C\left(n_{i}-m-1\right)-C\left(n_{i}\right)\left(n_{i}-m\right) /(m+1) \geq 0$ for $m \leq n_{i}$. Now

$$
\frac{C(m)}{m+1}>\frac{C\left(n_{i}\right)}{n_{i}+1}, \frac{C\left(n_{i}-m-1\right)}{n_{i}-m}>\frac{C\left(n_{i}\right)}{n_{i}+1}
$$

for $0 \leq m<n_{i}$ implies $C(m)+C\left(n_{i}-m-1\right) \geq C\left(n_{i}\right)$ for $0 \leq m \leq n_{i}$ and this together with (1) implies

$$
C\left(m_{i}\right) \geqq A\left(m_{i}\right)+B\left(m_{i}\right)-1 .
$$

Modifications analogous to those applied in the present paper to the proof of the authors Fundamental Theorem [3] can also be applied to Dyson's [1] proof of its generalization to more than two sets. The special case of Dyson's Theorem considered here then reads:

If $C=A_{1}+\cdots+A_{g}$ and if $c_{0}, a_{0 i}$ are the smallest elements in $C$ and $A_{i}$ respectively, then for $n \geq c_{0}$, there is an $m$ such that

$$
\begin{aligned}
& \frac{C(n)}{n-c_{0}+1} \geq \frac{\sum A_{i}\left(m-c_{0}+a_{0 i}\right)-(g-1)}{m-c_{0}+1} \\
& c_{0} \leq m \leq n .
\end{aligned}
$$

This inequality with $a_{0}=b_{0}=0$ was first obtained by Kneser [4, Theorem VII]. Inequality (11) for $g=2$ already known to van der Corput [5] is somewhat weaker than Theorem 2, because the minimum is not restricted to $m \notin C$. This weakening is necessary if $g>2$. The relation (11) with $g \geq 3$ becomes false, if $m$ is not restricted to elements not in $C$. It is not known to the author if $C(n) /(n+1) \neq C(m) /(m+1)$ for $c_{0} \leq m<n$ and

$$
C(n)<\sum_{j} A_{j}\left(n-c_{0}+a_{0 i}\right)-(g-1)
$$

implies strict inequality in (11) when $g \geq 3$.

Clearly on account of (11), Theorems 3 and 4 , the latter without the condition $m \notin C$, carry over to the sum of an arbitrary number of sets.

The author takes the opportunity to refute Khintchine's [2] assertion that the methods used in his exposition are altogether different from those introduced in [3]. Anybody acquainted with the authors first proof must see that the basic ideas are exactly the same.

\section{REFERENCES}

1. F. J. Dyson, A theorem on the densities of sets of integers, J. London Math. Soc. 20, (1945), 8-14.

2. A. Y. Khinchin, Three pearls of number theory, Graylock Press, Rochester, New York (1952). 
3. H. B. Mann, A proof of the fundamental theorem on the density of sums of sets of positive integers, Ann. of Math. 43, (1942), 523-527.

4. Kneser Martin Abschaetzung der asymptotischen Dichte von Summen mengen, Math. Zeitschrift. Bd. 58, (1953), 459-484.

5. J. G. Van der Corput, On sets of integers I II III, Proc. Akad. Wet. Amsterdam 50, (1947), 252-261, 340-350, 429-435.

The OHIo State University 



\section{PACIFIC JOURNAL OF MATHEMATICS}

\section{EDITORS}

\author{
David Gilbarg \\ Stanford University \\ Stanford, California \\ F. H. Brownell \\ University of Washington \\ Seattle 5 , Washington
}

\author{
A. L. Whiteman \\ University of Southern California \\ Los Angeles 7, California \\ L. J. PAIGE \\ University of California \\ Los Angeles 24, California
}

\section{ASSOCIATE EDITORS}

\author{
E. F. BECKENBACH \\ T. M. CHERRY \\ D. DERRY
}
E. HEWITT
A. HORN
L. NACHBIN
M. OHTSUKA
H. L. ROYDEN
M. M. SCHIFFER

E. SPANIER

E. G. STRAUS

F. WOLF

\section{SUPPORTING INSTITUTIONS}

\author{
UNIVERSITY OF BRITISH COLUMBIA \\ CALIFORNIA INSTITUTE OF TECHNOLOGY \\ UNIVERSITY OF CALIFORNIA \\ MONTANA STATE UNIVERSITY \\ UNIVERSITY OF NEVADA \\ NEW MEXICO STATE UNIVERSITY \\ OREGON STATE COLLEGE \\ UNIVERSITY OF OREGON \\ OSAKA UNIVERSITY \\ UNIVERSITY OF SOUTHERN CALIFORNIA
}

\author{
STANFORD UNIVERSITY \\ UNIVERSITY OF TOKYO \\ UNIVERSITY OF UTAH \\ WASHINGTON STATE COLLEGE \\ UNIVERSITY OF WASHINGTON

AMERICAN MATHEMATICAL SOCIETY
CALIFORNIA RESEARCH CORPORATION
HUGHES AIRCRAFT COMPANY
SPACE TECHNOLOGY LABORATORIES
NAVAL ORDNANCE TEST STATION

Mathematical papers intended for publication in the Pacific Journal of Mathematics should be typewritten (double spaced), and the author should keep a complete copy. Manuscripts may be sent to any one of the four editors. All other communications to the editors should be addressed to the managing editor, L. J. Paige at the University of California, Los Angeles 24, California. ..

50 reprints per author of each article are furnished free of charge; additional copies may be obtained at cost in multiples of 50 .

The Pacific Journal of Mathematics is published quarterly, in March, June, September, and December. The price per volume (4 numbers) is $\$ 12.00$; single issues, $\$ 3.50$. Back numbers are available. Special price to individual faculty members of supporting institutions and to individual members of the American Mathematical Society: $\$ 4.00$ per volume; single issues, $\$ 1.25$.

Subscriptions, orders for back numbers, and changes of address should be sent to Pacific Journal of Mathematics, 2120 Oxford Street, Berkeley 4, California.

Printed at Kokusai Bunken Insatsusha (International Academic Printing Co., Ltd.), No. $6_{4}$ 2-chome, Fujimi-cho, Chiyoda-ku, Tokyo, Japan.

PUBLISHED BY PACIFIC JOURNAL OF MATHEMATICS, A NON-PROFIT CORPORATION

The Supporting Institutions listed above contribute to the cost of publication of this Journăl, but they are not owners or publishers and have no responsibility for its content or policies. 


\section{Pacific Journal of Mathematics}

\section{Vol. 10, No. $3 \quad$ November, 1960}

Glen Earl Baxter, An analytic problem whose solution follows from a simple

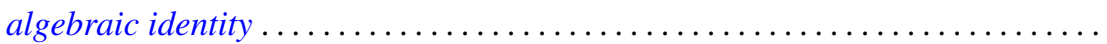

Leonard D. Berkovitz and Melvin Dresher, A multimove infinite game with linear payoff. .

Earl Robert Berkson, Sequel to a paper of A. E. Taylor ......................

Gerald Berman and Robert Jerome Silverman, Embedding of algebraic systems.... 767

Peter Crawley, Lattices whose congruences form a boolean algebra . . . . . ...... 777

Robert E. Edwards, Integral bases in inductive limit spaces . . . . . . . . . . . . . . .

Daniel T. Finkbeiner, II, Irreducible congruence relations on lattices . . . . . . . . . .

William James Firey, Isoperimetric ratios of Reuleaux polygons . . . . . . . . . . . 787

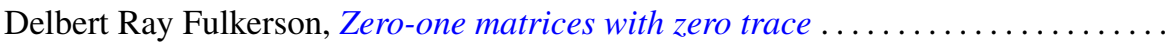

Leon W. Green, A sphere characterization related to Blaschke's conjecture........

Israel (Yitzchak) Nathan Herstein and Erwin Kleinfeld, Lie mappings in

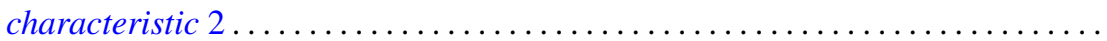

Charles Ray Hobby, A characteristic subgroup of a $p$-group .................

R. K. Juberg, On the Dirichlet problem for certain higher order parabolic

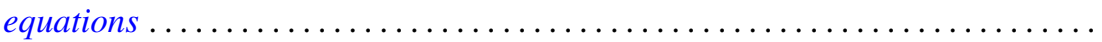

Melvin Katz, Infinitely repeatable games ......................

Emma Lehmer, On Jacobi functions . . . . . . . . . . . . . . . . . . . . . . . . .

D. H. Lehmer, Power character matrices

Henry B. Mann, A refinement of the fundamental theorem on the density of the sum of two sets of integers.

Marvin David Marcus and Roy Westwick, Linear maps on skew symmetric matrices: the invariance of elementary symmetric functions . .

Richard Dean Mayer and Richard Scott Pierce, Boolean algebras with ordered

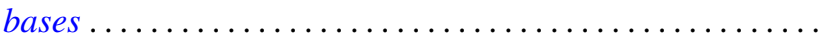

Trevor James McMinn, On the line segments of a convex surface in $E_{3} \ldots$

Frank Albert Raymond, The end point compactification of manifolds ..

Edgar Reich and S. E. Warschawski, On canonical conformal maps of regions of arbitrary connectivity

Marvin Rosenblum, The absolute continuity of Toeplitz's matrices...

Lee Albert Rubel, Maximal means and Tauberian theorems . .

Helmut Heinrich Schaefer, Some spectral properties of positive linear operators

Jeremiah Milton Stark, Minimum problems in the theory of pseudo-conformal transformations and their application to estimation of the curvature of the invariant metric.

Robert Steinberg, The simplicity of certain groups ...

Hisahiro Tamano, On paracompactness. .

Angus E. Taylor, Mittag-Leffler expansions and spectral theory .

Marion Franklin Tinsley, Permanents of cyclic matrices ...... . 